\title{
Team Flexibility in Organizational Change Context: Antecedents and Consequences
}

\author{
Bin Ling' \\ Ziqian Liu (D)' \\ Dusheng Chen ${ }^{2}$ \\ Lijun Sun ${ }^{3}$
}

'Business School, Hohai University, Nanjing, People's Republic of China;

${ }^{2}$ Hangzhou Hikvision Digital Technology Co., Ltd., Hangzhou, People's Republic of China; ${ }^{3}$ Arts College, Nanjing University of Aeronautics and Astronautics, Nanjing, People's Republic of China
Correspondence: Lijun Sun

Arts College, Nanjing University of

Aeronautics and Astronautics, 29 jiangjun

Avenue, Nanjing, 211106, People's

Republic of China

Email sunlijun327।@I26.com

Bin Ling

Business School, Hohai University,

Jiangning Campus, 8 Focheng West Road,

Nanjing, 2I I 100, People's Republic of

China

Tel +86-025-685I4352

Email ling.bin@hotmail.com
Purpose: The purpose of our study is to explore the antecedents and consequences of team flexibility in an organizational change context. In this regard, we considered team flexibility as an important theoretical mechanism under which the insiders would adapt to organizational change.

Participants and Methods: A sample of 602 individual data that was nested in 108 teams and 43 organizations was used in this study, collecting from 43 enterprises located in mainland China through questionnaires. We adopted HLM 6.08 to testify all the hypothesized relationships and used the Monte Carlo method to create the confidence intervals for all the indirect effects.

Results: The empirical results show that 1 ) balance dimension of ambidexterity and change leadership have a significant positive effect on team flexibility; 2) balance dimension of ambidexterity only has marginal significant effects on employee change-specific adaptive behavior, change-specific proactive behavior, and change fairness. And change leadership has significant positive effects on the three outcomes; 3) team flexibility has a positive influence on the three outcomes. 4) Team flexibility plays a significant mediating role in the links between the balance dimension of ambidexterity and the three outcomes. In addition, team flexibility only has a significant indirect effect on the relationship between change leadership and change-specific adaptive behavior and proactive behavior.

Conclusion: The current study reveals how team flexibility is established and how such flexibility is associated with employee-level change-specific behavior and perception under an organizational change context. The study indicates that team flexibility is contingent on two factors across two levels: change leadership at team level and balanced ambidexterity at organizational level, which also contributes to individual outcomes of organizational change. Keywords: team flexibility, balance dimension of ambidexterity, change leadership, adaptive behavior, change fairness, proactive behavior

\section{Introduction}

Environmental uncertainty and turbulence are spread over the process of organizational change and transformation, which lay a hidden danger for enterprises to successfully achieve their expected goals. ${ }^{1-3}$ Exploring the ability to adapt to uncertain and turbulent environments has become an important research focus for scholars in the field of organizational change. Previous study has appealed to enterprises to establish the ability necessary to manage the environmental uncertainty and turbulence. ${ }^{3}$ This critical ability has become integral to organizational survival. ${ }^{4}$ Since research has conducted ongoing efforts to investigate how organizations adapt their practices to a changing, dynamic and uncertain environment, ${ }^{4-7}$ 
team flexibility becomes a critical force boosting adaptation, countering rigidity, and achieving competitive advantages. $^{8-10}$

Team flexibility, defined as the ability to cope with environmental uncertainty, ${ }^{8,11}$ enables enterprises to survive and develop from organizational change and transformation. In previous research, scholars have found that team flexibility is an important predictor of organizational productivity, competitive advantage, and problem-solving ability in the uncertain and turbulent context. ${ }^{8,11,12}$ Team flexibility is also helpful for teams to carry out threats effectively from uncertainty and turbulence. ${ }^{8,13}$ Although previous research has acknowledged the importance of team flexibility, we seldom adequately understand the ways in which team flexibility is established under organizational change context and how it then affects the consequences of organizational change. The purpose of this study is to explore under what conditions team flexibility will be enhanced or weakened and how team flexibility affects individual outcomes of organizational change. Team flexibility is treated as one of the central mechanisms of organizational capacity to respond to changing environments.

In order to adapt organizational change, enterprises should develop their organizational capacities to effectively coordinate resources and require an effective leadership to lead organizational change. ${ }^{14-17}$ These characteristics allow team flexibility to be established under change context. While previous work has indicated that team flexibility is associated with individual antecedents like personality ${ }^{18}$ and within-team competition, ${ }^{8}$ team flexibility is more likely to be related to team-level and organization-level antecedents. In the current study, we mainly focus on two potential antecedents that are associated with team flexibility across team and organization levels. The first potential antecedent is organizational ambidexterity, which scholars define as a dynamic capability to configure organizational resources by balancing existing as well as new assets and opportunities. ${ }^{19,20}$ Drawing on the theory of dynamic capability, ${ }^{21}$ organizational ambidexterity is central to the adaptive process of organizational change and may be one of the key predictors of team flexibility. In this paper, we use a balanced approach to conceptualize organizational ambidexteritybalance dimension of ambidexterity. Change leadership, as a change-specific leader behavior in terms of implementing organizational change,,$^{22,23}$ is another potential antecedent in team flexibility. As previous research stated, ${ }^{15,24}$ change leadership is useful to develop a change-adept organization via preparing change well, conducting flexible communication and learning program. The existing literature on team flexibility has not yet examined whether team flexibility is associated with organizational ambidexterity and change leadership. This study seeks to fill this gap via exploring the two potential antecedents of team flexibility.

While previous studies have shown that team flexibility promotes many organizational benefits, such as new product development, ${ }^{25}$ team performance, ${ }^{26,27}$ project performance, ${ }^{28}$ and organizational innovation, ${ }^{29}$ the existing literature on team flexibility has not yet examined how team flexibility may influence the outcomes of organizational change. This current study seeks to fill this gap by investigating the association between team flexibility and three outcomes of organizational change. The three outcomes are referred to as change-specific adaptive behavior, proactive behavior, and change fairness; they are measured and embedded in the organizational change context. This study extends our understanding of team flexibility's effects under the organizational change context by providing evidence that individual change-specific adaptive behavior, proactive behavior, and change fairness vary with the strength of team flexibility.

This paper contributes to both team flexibility and organizational change literature in the following ways. First, we investigate whether organization-level capacity and team-level leadership antecedents are related to team flexibility. To our knowledge, this is the first paper to explore how to establish team flexibility from the perspective of organizational change. To ascertain the organization-level antecedent, we examine whether balance dimension of organizational ambidexterity predicts team flexibility. According to the dynamic capacity approach, ambidexterity balancing exploration and exploitation is central to the adaptive process because organizational resources can be configured reasonably, ${ }^{30}$ which is the foundation of team flexibility. The antecedent of change leadership implies that these change-specific leaders who talk of the specific change programs at hand are predictors of team flexibility. In so doing, we extend team flexibility research by shifting the leadership-flexibility relationship to the organizational change domain. Ideally, changing organizations should induce teams to be flexible by establishing balanced ambidexterity and change leadership. 
Second, we demonstrate how team flexibility may bring broader benefits to a changing organization and extend the research on the outcomes of organizational change. Central to the consequences of team flexibility is to test whether team flexibility helps employees better adapt to organizational change. The three outcomes of organizational change reflect the degree to which employees adapted to organizational change. Our study provides evidence that flexibility is considered as an effective practice within the process of change. In addition to investigating how team flexibility links both balance dimension of ambidexterity and change leadership to change outcomes, this study also seeks to understand how it mediates the impact of balance dimension of ambidexterity and change leadership on three change outcomes, which includes change-specific adaptive behavior, proactive behavior, and change fairness. We believe this mediation role extends team flexibility literature by providing a new theoretical explanation for the adaptive process of organizational change. The findings of this paper indicate that we should understand and advise managers as to how they balance ambidextrous capacities and develop change leadership to promote desired change outcomes via the progress of team flexibility.

\section{Theoretical Development and Hypotheses Team Flexibility}

Team flexibility refers to the ability of a team to adapt to the changes and turbulence of the environment. ${ }^{12,27}$ Team flexibility can change the behavioral and cognitive structure of team members and enable the whole team to respond to the changes and demands of the work environment in a flexible way rather than a mechanical way. With the rapid changes in task and organizational environment, organizations require a management ability and mechanism that can quickly adapt and respond flexibly. Flexibility in organization was originally rooted in the literature on strategic flexibility and human resource flexibility, ${ }^{31,32}$ which emphasized the organizational process from the strategic analysis and the ability to adapt to a changing environment. Compared with research on strategic and human resource flexibility, the research on team flexibility started relatively late and is limited. The application of team flexibility is that work team is a basic unit for any organizations to take flexible actions against environmental uncertainty and disturbance. Unlike the flexibility literature that has examined flexibility at the organizational level, the team flexibility's conceptualization is implicitly at the group level.

The core of team flexibility is the ability to quickly adapt to environmental changes by regulating within-team behavioral and cognitive pattern. As previous research has pointed out, ${ }^{8}$ high flexible work team can take the initiative to improve their original working routines, encourage internal knowledge sharing and interaction, and adjust the implicit operation rules, when necessary, which ensures that this team enables the expected goals to be achieved under the changing environment. In addition, flexibility can also encourage team members to treat and resolve problems in a creative manner. ${ }^{26,29}$ This current study assumes that organizational change sets a desired research context for team flexibility, and it will become more necessary to explore how team flexibility is established and how important team flexibility is to improve the outcomes of organizational change. In other words, team flexibility provides a novel theoretical explanation to understand how employees adapt and respond to a changing organization.

\section{Antecedents of Team Flexibility}

According to March, $^{33}$ organizational ambidexterity includes two different but related dimensions - exploration and exploitation. The former refers to exploring new resource, knowledge and opportunities, whereas the latter involves developing existing resources and competencies. ${ }^{33}$ Both activities can bring benefits to organization. Previous research has stated that how organizational ambidexterity works depends on the way of how exploration and exploitation are blended. ${ }^{34,35}$ Organizational ambidexterity has been termed from two different conceptualizations of exploration and exploitation, ${ }^{20,34,36}$ one involving balancing exploration and exploitation, namely, the "balance dimension of ambidexterity" (BD), and the other involving combining their magnitude, namely, the "combined dimension of ambidexterity" (CD). BD is calculated by the absolute value of exploration and exploitation, and thus it mainly reflects the relative magnitude of the two activities; BD considers exploration and exploitation as a competitive relation. ${ }^{20,34} \mathrm{CD}$ reflects the absolute magnitude of exploration and exploitation, which makes the two activities be mutually complementary. ${ }^{34}$ The significance of BD and $\mathrm{CD}$ to organizational effectiveness is contingent on the available resources of an organization. Cao et $\mathrm{al}^{34}$ 
proposed that $\mathrm{CD}$ is more effective when internal or external resources are abundant, whereas $\mathrm{BD}$ is more effective when resources are constrained in the environment. Because the resource-constrained nature is relatively salient under the organizational change context, this current study used $\mathrm{BD}$ to conceptualize the ambidexterity construct. Previous research has indicated that BD is beneficial to organizational performance and competitive advantage. ${ }^{33,34,36,37}$ We believe that $\mathrm{BD}$ is a better strategy to understand how ambidexterity works in the organizational change process.

Balancing exportation and exploitation has been considered as one of the most important strategies to improve organizational adaptability and flexibility. ${ }^{30,38,39}$ Because this balanced strategy is helpful to control organizational risk, it is not conducive to the survival and development of a firm when managers overemphasize exploration or exploitation. ${ }^{34,38}$ Levinthal and March $^{38}$ have proposed that a firm that overemphasizes exclusive exploration at the expense of exploitation will suffer the risk of unsustainability, whereas a film that indulges in exploitation at the expense of exploration will suffer the risk of obsolescence. The capacity for flexibility and adaptability is positively associated with a balanced mix of exploration and exploitation. From the perspective of dynamic capacity, ${ }^{19}$ ambidexterity can reconfigure internal and external resources and competencies in a balance manner, which was found to be positively related to team flexibility in another empirical research. ${ }^{40}$

In line with the above reasoning, we propose that $\mathrm{BD}$ may be positively associated with team flexibility, which ensures survival and viability in the face of organizational change. ${ }^{12,27}$ Making a balance between exploration and exploitation is beneficial for team flexibility because $\mathrm{BD}$ enables organizations to make more leeway to pursue sustainable goals from organizational learning and distribute reasonable resources to work teams facing organizational uncertainty. Work unit under the high BD condition is not susceptible to the risk or failure of adaptation to organizational change. Building on this logic, we propose that BD may be an organization-level predictor of team flexibility.

H1: BD is positively related to team flexibility.

Change leadership is a change-specific leader behavior that mainly focuses on the way of how to lead a change program from a tactic view. ${ }^{17,22,41}$ This concept has received much research attention in organizational field, which has explored many organizational outcomes, such as commitment to change, ${ }^{17,22,42}$ intention to support planned change, ${ }^{43}$ work engagement, ${ }^{44}$ and firm performance. ${ }^{45}$ In line with previous organizational change management literature, the function of change leaders lies in communicating a vision to direct the change efforts, establishing collective identification with change, resolving employees' sense of crisis and resistance to change. ${ }^{17,22,23,46}$ We believe that change leadership enables work teams to take adaptive and flexible actions to handle organizational change for several reasons. First, change leaders provide a clear guidance for team members on how to be flexible under organizational change and inform their members of specific strategies to adapt to and perform the change. ${ }^{24,46}$ The collectives who want to be flexible require their team leaders' action and communication as clearly as possible. Second, change leadership is a contextual adaptation process where change leaders can encourage team to make adaptive adjustment to the change requirements once they find demands from change. ${ }^{22}$ Under the influence of change leaders, team members may show their flexibility and adaptability to handle organizational change. Finally, change leaders lead a change by serving as role models and subordinates regulate their behaviors to match their role models. ${ }^{46}$ As a role model, change leaders should be more flexible when they lead successfully a reform or transformation, otherwise, their efforts probably fail. ${ }^{16}$ As change recipients, team members take their role models' change behaviors as the reference to adjust themselves adaptively to a change situation, as a result, which may improve team flexibility.

$\mathrm{H} 2$ : Change leadership is positively related to team flexibility.

\section{Consequences of Team Flexibility}

As the above description stated, team flexibility is the ability to adapt to a changing environment, and has been considered as a key facilitator of organizational change. ${ }^{10,29}$ Flexibility matters in organizational change because it has been used as a rationale for organizational change as well as a desired organizational characteristic. ${ }^{9}$ However, considering the important role of flexibility in organizational change, it is poorly understood whether team flexibility empirically impacts organizational change outcomes. Exploring the association between team 
flexibility and organizational change outcomes is another goal in the current research. Organizational change outcomes reflect the extent to which organizational change activities influence organization-level performance and development as well as employees' individual-level behavior and attitude. ${ }^{47,48}$ However, this present study only focused on the individual-level outcomes of organizational change. In line with previous research, ${ }^{17,22,48}$ our study used employees' change-specific behavior and attitude as the individual outcomes of organizational change. Specifically, the individual outcomes of organizational change include change-specific adaptive behavior, proactive behavior, and fairness perception. Change-specific adaptive behavior refers to the extent to which employees adapt to organizational change activities; ${ }^{7,49}$ changespecific proactive behavior refers to the extent to which employees actively participate in organizational change activities; ${ }^{49-52}$ change fairness reflects the extent to which employees perceive the fairness of organizational change process. ${ }^{53,54}$ This study considers these three change-specific variables as the potential consequences of team flexibility, which reflects a basic research question of how team flexibility influence employees' individual response to change.

First, we hypothesize that team flexibility is positively associated with change-specific adaptive behavior According to previous research, ${ }^{12,27}$ the adaptive function of team flexibility is associated with improving team members' cognitive and behavioral pattern consistent with requirements of a changing environment, and removing barriers for employees to adjust themselves to a new work situation. ${ }^{55,56}$ Under the influence of team flexibility, team members can frame problems in a new way and work out creative solutions when they encounter organizational change. ${ }^{26,29}$ This creative adjustment reflects team members' adaptive response to the changing environment. Hence, we believe team flexibility enables team members to enhance individual behavior to adapt to organizational change.

Second, we consider that team flexibility is positively related to change-specific proactive behavior. Conceptually, flexibility is a proactive capacity of an organization to manage changes from environment; ${ }^{57}$ this means flexibility enables team members to take measures in advance to handle organizational change. Previous studies also reveal that a flexible team can make its members to take proactive or offensive actions in response to environmental changes and uncertainty. ${ }^{8,27}$ In addition, from a discourse perspective, ${ }^{9}$ flexibility has connotations of autonomy and freedom of choice such that employees can obtain more room to participate in the process of organizational change when they belong to a flexible team. Considering the above reasoning, we believe that team flexibility enables employees to take the initiative during the organizational change process.

Finally, we propose that team flexibility is positively associated with a sense of change fairness. Employees who think they are fairly treated have positive views on organizational change ${ }^{53,58}$ This fairness perception is based on organizational characteristics, such as centralization and formalization. According to the research by Schminke, Cropanzano, and Rupp, ${ }^{59}$ fairness perception is positively associated with the organizational structure lower in centralization or higher in formalization. Flexibility is a core characteristic associated with new organizational structure that is presented as disaggregating hierarchy and centralized bureaucracy. ${ }^{9}$ This flexible environment provides autonomy and participation for team members to know the information and progress in the organizational change process. In this way, team members do not fear the key information on organizational change will be obscured and distorted by the organizational centralization and hierarchy; instead, they are more likely to perceive the organizational change process as fair. Based on the above arguments, we propose the following hypotheses.

H3a: Team flexibility is positively related to changespecific adaptive behavior.

H3b: Team flexibility is positively related to changespecific proactive behavior.

H3c: Team flexibility is positively related to change fairness.

\section{Team Flexibility as a Mediator}

Considering the links from $\mathrm{BD}$ and change leadership to team flexibility and the links from team flexibility to changespecific adaptive behavior, proactive behavior, and change fairness, we propose that team flexibility will automatically act as a mediator to connect BD and change leadership with three organizational outcomes. Previous research has indicated that $\mathrm{BD}$ and change leadership could bring benefits to organizational change. ${ }^{22,60}$ However, existing research on $\mathrm{BD}$ mainly examined its consequences at the organizational level, with little investigation of the consequences at the individual level. The mediation of team flexibility is helpful 
to connect $\mathrm{BD}$ and employees' individual change outcomes and understand the psychological process underlying their connections. Change leadership has been considered as a facilitator of individual change-specific behavior and perception in the previous research. ${ }^{17,22,43}$ Team flexibility may provide a new explanation for the way of how change leadership impacts employees' change-specific adaptive behavior, proactive behavior, and change fairness. Although team flexibility has been found to play a mediating role in the examination of team effectiveness ${ }^{27}$ and software development, ${ }^{12}$ little research has investigated the mediating effect of team flexibility on the relationship between change leadership or organizational ambidexterity and follower change outcomes at the individual level. As stated above, team flexibility matters to organizational change and establish a potential mediating mechanism to explain how to assist followers in responding to organizational change (see Figure 1). This produces the following hypotheses:

H4: Team flexibility mediates the positive association between $\mathrm{BD}$ and ( $\mathrm{H} 4 \mathrm{a})$ change-specific adaptive behavior, (H4b) change-specific proactive behavior, and (H4c) change fairness.

H5: Team flexibility mediates the positive association between change leadership and (H5a) change-specific adaptive behavior, (H5b) change-specific proactive behavior, and (H5c) change fairness.

\section{Method}

\section{Participants and Procedure}

This study completed the data collection from 43 enterprises located in mainland China. The criteria for selecting samples lie in whether the enterprise implemented at least one specific organization change or not, while the departments and employees who took part in their change initiative were targeted as the subject of this research. Due to the multilevel attributes of our model, we adopted the multilevel and multi-source approach to collect the nested data from individual employees and their team leaders. This approach to collect data is beneficial for reducing threats of common method bias following the recommendation of Podsakoff et al. ${ }^{61}$ All the measurements include three levels of questionnaires: the organization-level variables refer to organizational ambidexterity (exploration and exploitation) and enterprise demographics, which were mainly evaluated by team or department leaders; the department-level variables contain change leadership and team flexibility, which were mainly reported by individual employees; the individual-level variables involve change outcomes

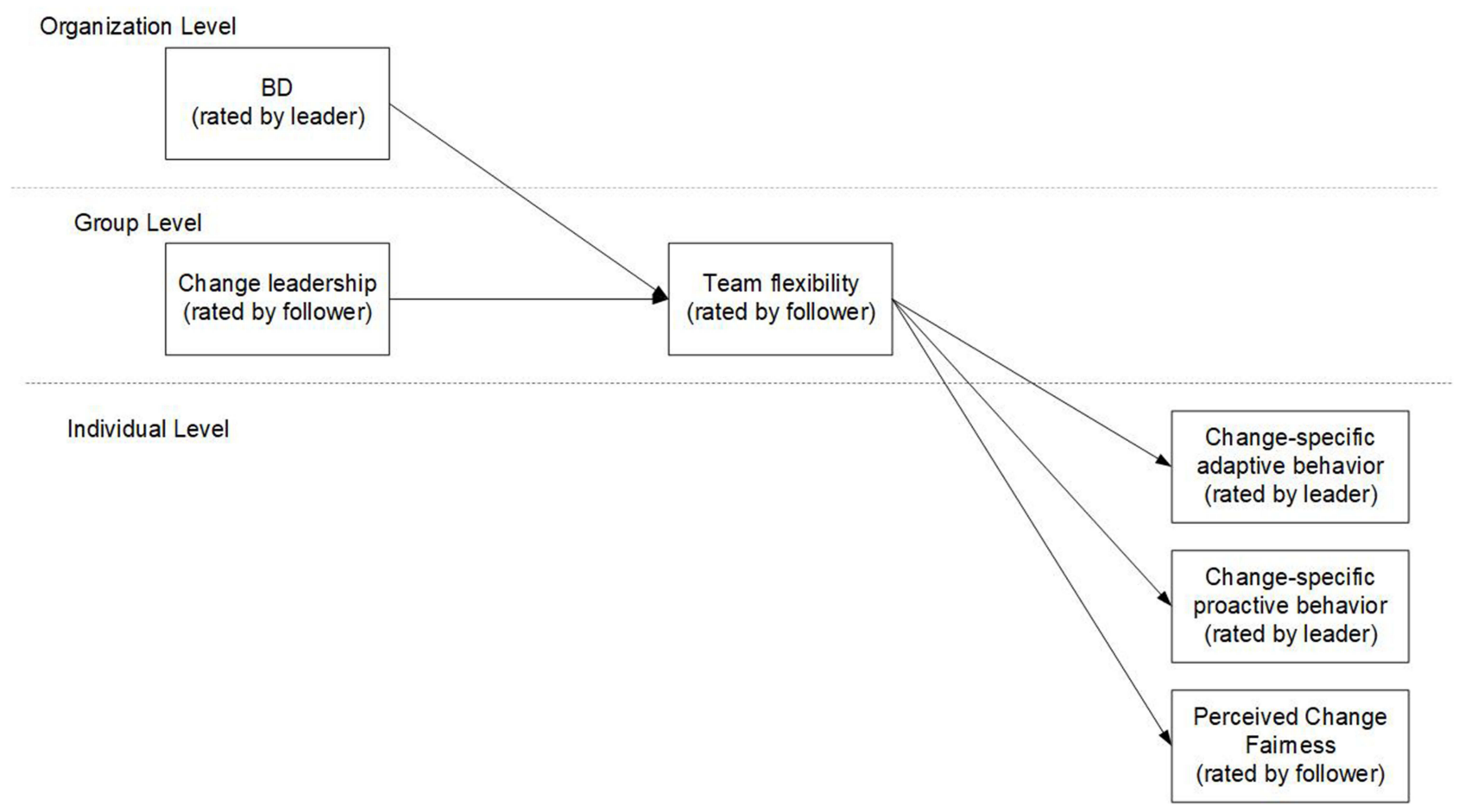

Figure I Theoretical framework.

Abbreviation: BD, balance dimension of ambidexterity. 
of employees, namely change-specific adaptive behavior, proactive behavior and change fairness, the first two outcomes were rated by team leaders, while the last outcome was self-reported by employees. Following the principle of the Declaration of Helsinki, our study was reviewed and approved by the Ethical Committee of Hohai University. All participants in this study completed an informed consent form and informed them about the confidentiality of their response.

The sampling procedure was completed under the help of human resource managers in every company. One of our authors first contacted each human resource manager and asked permission to collect data at their company. They were provided with the details about sampling procedures and standards before distributing questionnaires to participants. These managers selected the departments and employees who joined at least one change activity about company issues as our targeted subjects. A total of 800 sets of questionnaires were distributed to employees, while 120 departments and 45 organizations were included. The questionnaires that have missing values were deleted. Finally, we obtained a valid sample of 602 sets of individual questionnaires, which were nested into 108 departments and 43 companies (effective recovery rates are $75.3 \%$ at individual level, $90 \%$ at department level, and $95.6 \%$ at company level). Every company has an average of 14 employees and 2.5 departments, while every department has an average of 5.6 employees. There are a wide range of change activities in the 43 companies, such as product and service upgrading, brand building, technology innovation, diversification, business model innovation, merger and acquisition, globalization, restructuring, remanufacture, and so on.

Among the individual sample, it included 51.9\% male and $48.1 \%$ female employees. The average age and tenure were 30.7 years old $(\mathrm{SD}=5.97)$ and 4.5 years $(\mathrm{SD}=4.15) .55 .5 \%, 19.6 \%$ and $14.6 \%$ of employees received 4-year undergraduate, 3-year college, and graduate education, respectively. Among the department sample, $65.7 \%$ of the sample were male supervisors, the average age and tenure of all supervisors were 37.9 years old $(\mathrm{SD}=6.76)$ and 8.99 years $(\mathrm{SD}=5.83)$. The average size of departments had 24.8 members (SD = $35.64)$. As for the company size, 13 companies (30.2\%) have more than 2000 employees, 9 companies $(20.9 \%)$ have 500-2000 employees, and 12 (27.9\%) have 100 500 employees.

\section{Measurements}

In this study, most constructs in the research model were measured with multi-item scale measurements, which had been validated in the previous research. All the scale items were answered from a range from $1=$ strongly disagree to $5=$ strongly agree.

\section{Organizational Ambidexterity}

We used a scale derived by Patel et $\mathrm{al}^{62}$ to measure organizational ambidexterity that contains two dimensions: exploration and exploitation. The scale of exploration reflected the ability to improve organizational change and development through seeking external resource and creating new technologies, which focuses on continuous innovation. Sample items are "Looks for novel technological idea by thinking "outside the box", "Creates products or services that are innovative to the firm". The scale of exploitation was used to measure the ability to improve organizational change and development through refining existing resources, knowledge, and technologies within organization, which focuses on the development of existing resources and capabilities. Sample items are "Penetrates more deeply into its existing customer base", "Commits to improve quality and lower cost". The Cronbach's $\alpha$ for exploration and exploitation were 0.85 and 0.87 , respectively.

Following the recommendation of Cao et al, ${ }^{34}$ we used the balance approach to define the concept of ambidexterity. BD reflected the relative importance of exploration and exploitation, the absolute values of which were used to manipulate the quantization of ambidexterity. The range of the absolute values was from 0 to 1.5. In order to interpret the data better, we reversed the conversion of the absolute values by subtracting each absolute value by the highest scale score (ie, 5). A higher value reveals a greater BD. The conversion formula is as follows.

$$
\mathrm{BD}=5-\mid \text { Exploration }- \text { Exploitation } \mid
$$

\section{Change Leadership}

We used a scale originally developed by Herold et $\mathrm{al}^{22}$ to measure the behavior of change leadership. This scale reflected a set of change-specific actions and performances of a leader when implementing specific organizational change projects. There was a lead-in before the scale items: "Related to the specific change being studied, my department leader ...". Sample are " ... developed a clear vision for what was going to be achieved by our work 
unit", "made it clear up front to those in our unit why the change was necessary". The results of confirmatory factor analysis (CFA) indicated that change leadership had an acceptable construct validity (CFI $=0.978, \mathrm{TLI}=0.956$, RMSEA $=0.110$, SRMR $=0.021)$. The Cronbach's $\alpha$ was 0.91 .

\section{Team Flexibility}

A four-item scale derived by $\mathrm{He}$ et $\mathrm{al}^{8}$ was used to measure team flexibility. This scale reflected the extent to which a team adapted to unexpected changes in organizational change projects. Sample items are "Our team members are flexible with respect to our team's request for organizational changes", "Our team members are able to make any adjustments necessary to cope with changing circumstances". In order to keep the concept of team flexibility in the context of organizational change, we made some bit adjustments to the items from the original scale, which modified the general events into the organizational change events. The result of CFA indicated that team flexibility had a very good construct validity $(\mathrm{CFI}=$ 0.997, TLI $=0.992$, RMSEA $=0.052$, SRMR $=0.009$ ). The Cronbach's $\alpha$ was 0.88 .

\section{Organizational Change Outcomes}

We used the scale of change-specific adaptive behavior, proactive behavior, and change fairness as an integrated measurement of organizational change outcomes. The scales of adaptive behavior and proactive behavior were from Griffin et $\mathrm{al}^{49}$ and contained three items, respectively. The measurement of adaptive behavior was specific to the organizational change context and reflected the extent to which employees could adapt to changes in core tasks caused by an organizational change project. In order to highlight the change-specific of employees' adaptability, we added a lead-in of "During the transformation of this enterprise, this employee ..." before the items. The three items are " ... adapted well to changes in core tasks", " ... coped with changes to the way he/she has to do the core tasks", and " ... learned new skills to help he/she adapt to changes in your core tasks". The Cronbach's $\alpha$ was 0.77 .

The three-items of proactive behavior reflected the extent to which employees could actively initiate and participate in change projects. We also added a lead-in of "During the transformation of this enterprise, you ..." before the three items, which makes employee proactive behavior specific to a change context. The three items of proactive behavior are “ ... initiated better ways of doing your core tasks", “ ... come up with ideas to improve the way in which your core tasks are done", and "... made changes to the way your core tasks are done" The Cronbach's $\alpha$ was 0.77 .

The three-item measurement of perceived change fairness was from Caldwell et $\mathrm{al}^{53}$ and reflected employees' perception of fairness in the implementation process of organizational transformation and changes. The three items were also situated in organizational change context. The expression of three items is "sufficient advanced notice was given to employees affected by the change", "those affected by the change had ample opportunities for input", and "the organization kept everyone fully informed during the change". The Cronbach's $\alpha$ was 0.86 .

We conducted a CFA analysis before integrating the three scales into a higher-order concept of organizational change outcomes. The CFA result has indicated that the integrated concept of organizational change outcomes had a very great fit with our data $(\mathrm{CFI}=0.953$, TLI $=0.930$, RMSEA $=0.089$, SRMR $=0.039)$.

\section{Controls}

Following previous research that controlled some covariates to improve statistical estimates for our hypothesized effects, we chose employee sex (male $=1$ and female $=0$ ), tenure (self-report), education (high school and below $=1$, three-year diploma $=2$, undergraduate college $=3$, postgraduate and above $=4$ ), and firm size (50 employees and below $=1,51-100$ employees $=2,101-500$ employees $=$ 3, 501-2000 employees $=4$, more than 2000 employees $=5$ ) as the control variables in our model.

\section{Confirmatory Factor Analysis and Common Method Bias}

We used Mplus 7.4 to test the confirmatory factor analysis and common method bias. Since organizational ambidexterity is a global construct model in this paper and has only one value in each sampled enterprise, we did not include it in the analysis at this stage. Therefore, we only performed the tests of confirmatory factor analysis and common method bias for the other five variables. Our hypothesized model includes these five variables - change leadership, team flexibility, change adaptive behavior, proactive behavior, and perceived change fairness. The findings of confirmatory factor analysis indicated that hypothesized model had an excellent fit with our data (CFI $=0.959$, 
Table I Confirmatory Factor Analysis Results

\begin{tabular}{|l|r|r|r|r|}
\hline Model & \multicolumn{1}{l|}{ CFI } & \multicolumn{1}{l|}{ TLI } & \multicolumn{1}{l|}{ RMSEA } & \multicolumn{1}{l|}{ SRMR } \\
\hline $\begin{array}{l}\text { Hypothesized } \\
\text { model }\end{array}$ & 0.959 & 0.930 & 0.059 & 0.041 \\
\hline $\begin{array}{l}\text { Four-factor } \\
\text { model }^{\text {a }}\end{array}$ & 0.861 & 0.835 & 0.106 & 0.067 \\
\hline $\begin{array}{l}\text { Four-factor } \\
\text { model }\end{array}$ & 0.834 & 0.803 & 0.116 & 0.087 \\
\hline $\begin{array}{l}\text { Four-factor } \\
\text { model }\end{array}$ & 0.885 & 0.863 & 0.097 & 0.067 \\
\hline $\begin{array}{l}\text { Three-factor } \\
\text { model }\end{array}$ & 0.823 & 0.794 & 0.119 & 0.098 \\
\hline $\begin{array}{l}\text { Two-factor } \\
\text { model }\end{array}$ & 0.728 & 0.689 & 0.146 & 0.108 \\
\hline $\begin{array}{l}\text { Single-factor } \\
\text { model }\end{array}$ & 0.653 & 0.607 & 0.165 & 0.110 \\
\hline
\end{tabular}

Notes: four-factor model ${ }^{\mathrm{a}}=$ integrating change leadership and team flexibility into one factor, change adaptive behavior, proactive behavior, and perceived change fairness; four-factor model ${ }^{b}=$ integrating change proactive behavior and perceived change fairness into one factor, and the other three variables; four-factor model ${ }^{c}=$ integrating team flexibility and change adaptive behavior into one factor, and the others; three-factor model = integrating change adaptive behavior, proactive behavior, and perceived change fairness into one factor, change leadership, and team flexibility; two-factor model = integrating change leadership and team flexibility into one factor while integrating the others into another factor; single-factor model = integrating all variables into one single factor.

$\mathrm{TLI}=0.930, \mathrm{RMSEA}=0.059, \mathrm{SRMR}=0.041)$ compared with other alternative models, see Table 1.

We used the unmeasured common latent factor method $^{61}$ to check the potential common method bias. A common latent factor was constructed to load all indicators of the latent factors with the unmeasured common latent factor method, and the regression weight between the indicators and the common latent factor was set as equal, while the variance of the common latent factor was set as 1 . We obtained the common variance, which is equal to the square of the common latent factor loadings. The value of the common variance is $0.23\left(0.48^{2}\right)$ which is less than $50 \%$ of the threshold limit. ${ }^{63,64}$ In a word, there is no serious common method bias in this current study.

\section{Aggregation Test}

Because change leadership and team flexibility have shared unit properties, they were aggregated from the scores at the individual level. Before aggregation, we should calculate $R_{\mathrm{wg}}, \mathrm{ICC}_{1}$, and $\mathrm{ICC}_{2}{ }^{65,66}$ to justify the aggregation test. The results indicated that the aggregation of change leadership was supported with employee data $\left(\mathrm{ICC}_{1}=0.23, \mathrm{ICC}_{2}=0.65, R_{\text {wgmedian }}=0.94\right)$, while the aggregation of team flexibility also obtain a good support $\left(\mathrm{ICC}_{1}=0.14, \mathrm{ICC}_{2}=0.48, R_{\text {wgmedian }}=0.95\right)$. The values of $\mathrm{ICC}_{1}$ and $R \mathrm{wg}$ still offered strong evidence to support data aggregation of these two variables, although the values of $\mathrm{ICC}_{2}$ were less than $0.70 .^{67}$ Organizational ambidexterity, measured by a senior executive in each company, is a global indicator at company level and did not conduct this aggregation test.

\section{Analytical Strategy}

Because our model included three levels-company-, department-, and individual-level, we used hierarchical linear modeling HLM, 6.08 version, ${ }^{68}$ to test the cross-level relationships and multilevel mediation effects. First, we conducted the null model tests (without any predictors) of all three outcome variables to test their between-group difference across companies and departments. For change proactive behavior, the between-company variance reached very significant, $\chi^{2}(42)=96.36, p<0.001, \mathrm{ICC}_{1}=0.08$, whereas the between-department variance was not significant, $\chi^{2}(65)=70.96, p=0.29, \mathrm{ICC}_{1}=0.02$. This result means that $8 \%$ variance in change proactive behavior resided between companies, and only $2 \%$ resided across departments. For change adaptive behavior, the betweencompany variance was very significant, $\chi^{2}(42)=68.43, p=$ $0.006, \mathrm{ICC}_{1}=0.04$, while the between-department variance reached a marginally significant, $\chi^{2}(65)=82.13, p=0.07$, $\mathrm{ICC}_{1}=0.06$. This result indicates that $4 \%$ and $6 \%$ variance resided across companies and departments, respectively. For perceived change fairness, the between-company variance was marginally significant, $\chi^{2}(42)=55.62, p=0.07, \mathrm{ICC}_{1}=$ 0.03 , while the between-department variance was significant, $\chi^{2}(65)=94.67, p=0.01, \mathrm{ICC}_{1}=0.10$. This result means that only $3 \%$ variance of perceived change fairness resided across companies and 10\% variance resided across departments. Overall, the results supported an approach of multilevel analysis in this study.

The current model includes multilevel mediation across two levels and three levels and cross-level moderation, which should be tested. Following the recommendation of Zhang et $\mathrm{al}^{69}$ and Pituch et al, ${ }^{70}$ we constructed a three-level linear model to calculate path coefficients among variables and calculate a product of coefficients (the coefficient from independent variable to mediator; the coefficient from mediator to outcome variable) to estimate multilevel indirect effect. The method of Monte Carlo was used to test the statistical 
significance and distribution of the multilevel indirect effects. ${ }^{71}$ Based on the suggestion of Preacher and Kelley, ${ }^{72}$ we also estimated the effect size of our multilevel indirect effects with the method of Completely Standardized Indirect Effect. The effect size was calculated with the formula as follows: $a b_{c s}=a b \frac{\sigma_{X}}{\sigma_{Y}}$, where $a b$ equals indirect effect, and $\mathrm{X}$ and $\mathrm{Y}$ refer to independent variable and dependent variable, respectively. The value of this effect size means that dependent variable increases or decreases $a b_{\mathrm{cs}}$ standard deviation for each unit of standard deviation that independent variable indirectly increases or decreases through mediator. ${ }^{72}$ We used the grand-mean centering method to center variables before entering regression model. We considered employee gender, tenure, education as individual-level control variables and company size as company-level variables when running our multilevel regression model.

\section{Result}

\section{Descriptive Statistics}

The results of Table 2 include all variables' mean, standard deviation, and zero-order correlations. At individual level, the three outcome variables (change adaptive behavior, proactive behavior, and perceived change fairness) all correlate with one another significantly at the 0.001 level. At department level, change leadership correlates with team flexibility $(r=0.72$, $p<0.001$ ), and both correlate with outcome variables aggregated to the department level. At company level, exploration correlates with exploitation $(r=0.57, p<0.001)$, but neither of them correlates with BD at a significant level ( $p s>0.05)$. BD correlates with change leadership $(r=0.40, p<0.05)$, team flexibility $(r=0.32, p<0.05)$ and outcome variables (adaptive behavior: $r=0.26, p<0.05$; proactive behavior: $r=$ $0.29, p<0.05$; perceived change fairness: $r=0.40, p<0.01$ ) which aggregated to the company level.

\section{Hypotheses Tests}

Table 3 reports the results of multilevel hypotheses using HLM. Hypothesis 1 predicted that BD would positively influence team flexibility across companies. Table 3 shows that the results from Model 2 support this hypothesis $(\gamma=$ $0.35, p<0.05)$. Hypothesis 2 predicted that change leadership would positively influence team flexibility, which was supported in Model $1(\gamma=0.55, p<0.001)$.

In addition, we also found that $\mathrm{BD}$ and change leadership would have positive total effects on outcome variables - change adaptive behavior, proactive behavior, and perceived change fairness. As results shown in Table 3,

Table 2 Descriptive Statistics and Zero-Order Correlations

\begin{tabular}{|c|c|c|c|c|c|c|c|c|c|c|c|c|c|}
\hline Variable & $M$ & $S D$ & $\mathbf{I}$ & 2 & 3 & 4 & 5 & 6 & 7 & 8 & 9 & 10 & II \\
\hline \multicolumn{14}{|l|}{ Employee level } \\
\hline I. Gender & 0.52 & 0.50 & - & -0.02 & $-0.13 * *$ & 0.01 & -0.00 & 0.05 & & & & & \\
\hline 2. Tenure & 4.47 & 4.15 & & - & $-0.12 * *$ & 0.00 & 0.04 & 0.00 & & & & & \\
\hline 3. Education & 2.74 & 0.83 & & & - & $0.09 *$ & 0.07 & 0.03 & & & & & \\
\hline 4. Adaptive & 4.18 & 0.58 & & & & - & $0.72 * * *$ & $0.29 * * *$ & & & & & \\
\hline behavior & & & & & & & & & & & & & \\
\hline $\begin{array}{l}\text { 5. Proactive } \\
\text { behavior }\end{array}$ & 4.15 & 0.59 & & & & & - & $0.26 * * *$ & & & & & \\
\hline 6. Change fairness & 3.62 & 0.77 & & & & & & - & & & & & \\
\hline \multicolumn{14}{|l|}{ Department level } \\
\hline $\begin{array}{l}\text { 7. Change } \\
\text { leadership }\end{array}$ & 4.01 & 0.45 & & & & $0.46 * * *$ & $0.52 * * *$ & $0.59 * * *$ & - & & & & \\
\hline 8. Team flexibility & 4.06 & 0.35 & & & & $0.53 * * *$ & $0.57 * * *$ & $0.37^{* * *}$ & $0.72^{* * *}$ & - & & & \\
\hline \multicolumn{14}{|l|}{ Company level } \\
\hline 9. Company size & 3.65 & 1.27 & & & & 0.14 & 0.19 & 0.20 & $0.32 *$ & 0.03 & - & & \\
\hline 10. Exploration & 3.95 & 0.54 & & & & 0.24 & 0.17 & 0.17 & -0.003 & 0.11 & 0.05 & - & \\
\hline II. Exploitation & 4.02 & 0.49 & & & & 0.13 & -0.01 & -0.09 & -0.18 & -0.03 & 0.23 & $0.57 * * *$ & - \\
\hline 12. BD & 4.66 & 0.34 & & & & $0.26 *$ & $0.29 *$ & $0.40 * *$ & $0.40 *$ & $0.32 *$ & $0.38 *$ & 0.18 & 0.08 \\
\hline
\end{tabular}

Notes: Correlations above the diagonal indicate analyses at the individual level $(N=602)$. Correlations below the diagonal indicate analyses at the department level $(N=$ 108) and the company level $(\mathrm{N}=43)$. $* p<0.05, *_{p}<0.01$, ***p $<0.001$. 


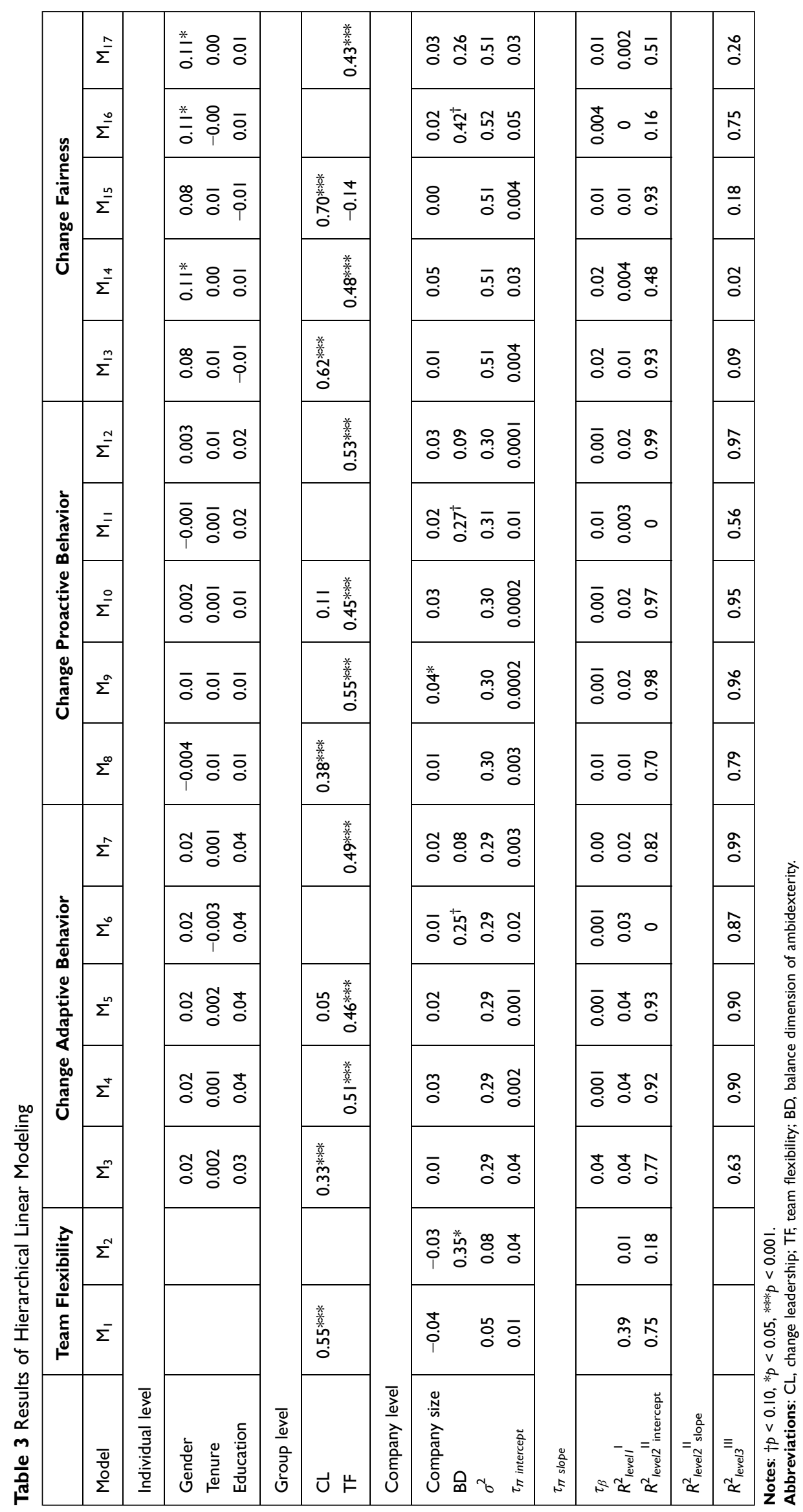


BD only had marginally significant effects on adaptive behavior $(\gamma=0.25, p=0.07)$, proactive behavior $(\gamma=$ $0.27, p=0.07)$, and perceived change fairness $(\gamma=0.42$, $p=0.08)$ at individual level. By contrast, change leadership had extremely significant effects on adaptive behavior $(\gamma=0.33, p<0.001)$, proactive behavior $(\gamma=0.38, p<$ $0.001)$, and perceived change fairness $(\gamma=0.62, p<$ $0.001)$.

We predicted that team flexibility would positively influence change adaptive behavior, proactive behavior, and perceived change fairness. As shown in Table 3, the positive effects of team flexibility on adaptive behavior (Model 4: $\gamma=0.51, p<0.001$ ), proactive behavior (Model 9: $\gamma=0.55, p<0.001)$, and perceived change fairness (Model 14: $\gamma=0.48, p<0.001$ ) were supported when control variables were included. Hence, hypotheses $3 \mathrm{a}, 3 \mathrm{~b}$ and $3 \mathrm{c}$ were supported.

The above-mentioned results indicated that $\mathrm{BD}$ and change leadership would significantly influence team flexibility, which supported the path coefficient from independent variable to mediator. In the following analyses, we should separately estimate the path coefficients from mediator to outcome variables, and the direct effects of BD and change leadership on the outcome variables when controlling for team flexibility and demographic factors.

Hypothesis 4 (H4a-H4c) sated that team flexibility would mediate the relationship between $\mathrm{BD}$ and the three outcome variables. The results indicated that $\mathrm{BD}$ did not hold significant relationships with adaptive behavior (Model 7: $\gamma=0.08, p>0.05$ ), proactive behavior (Model 12: $\gamma=0.09, p>0.05)$, and perceived change fairness (Model 17: $\gamma=0.26, p>0.05$ ) when team flexibility and control variables were included. Meanwhile, team flexibility held significantly positive effects on adaptive behavior (Model 7: $\gamma=0.49, p<0.001$ ), proactive behavior (Model 12: $\gamma=0.53, p<0.001)$, and perceived change fairness (Model 17: $\gamma=0.43, p<0.001$ ). In other words, team flexibility played a complete mediating role between $\mathrm{BD}$ and the three outcome variables.

Hypothesis 5 (H5a-H5c) stated that team flexibility would mediate the relationship between change leadership and the outcome variables. The results indicated that change leadership did not have a significant relationship with adaptive behavior (Model 5: $\gamma=0.05, p>0.05$ ) and proactive behavior (Model 10: $\gamma=0.11, p>0.05$ ), but had an increasing relationship with perceived change fairness (Model 15: $\gamma=0.70, p<0.001$ ). Meanwhile, team flexibility kept significant effects on adaptive behavior (Model
5: $\gamma=0.46, p<0.001$ ) and proactive behavior (Model 10: $\gamma=0.45, p<0.001$ ), but did not have a significant effect on perceived change fairness (Model 15: $\gamma=-0.14, p>$ $0.05)$. As a result, team flexibility may completely mediate the relationship between change leadership and adaptive behavior and proactive behavior, but does not mediate the relationship between change leadership and perceived change fairness.

In order to test the statistical significance of the multilevel indirect effects, we used the Monte Carlo method to estimate the confidence intervals (CIs, 95\% significant level). The results from Table 4 indicated that team flexibility would play significant mediating roles between BD and adaptive behavior $\left(a b=0.17, a b_{c s}=0.10,95 \% \mathrm{CIs}\right.$ $[0.03,0.33])$, proactive behavior $\left(a b=0.19, a b_{c s}=0.11\right.$, $95 \%$ CIs $[0.03,0.36])$, and perceived change fairness ( $a b=$ $0.15, a b_{c s}=0.07,95 \%$ CIs $\left.[0.02,0.31]\right)$. The range of values of CIs does not contain 0 , which is acceptable to support the significance of the indirect effects of team flexibility. And the indirect effects also had a good effect size. Hence, $\mathrm{H} 4 \mathrm{a}, \mathrm{H} 4 \mathrm{~b}$ and $\mathrm{H} 4 \mathrm{c}$ were supported.

The results from Table 4 also indicated that team flexibility only played significant mediating roles between change leadership and adaptive behavior $\left(a b=0.25, a b_{c s}\right.$ $=0.19,95 \%$ CIs $[0.13,0.39])$ and proactive behavior ( $a b=$ $0.25, a b_{c s}=0.19,95 \%$ CIs $\left.[0.15,0.35]\right)$. The results expressed an acceptable CIs and effect size. However, team flexibility did not mediate the relationship between change leadership and perceived change fairness $(a b=$ $-0.08, a b_{c s}=-0.05,95 \%$ CIs $\left.[-0.23,0.06]\right)$ and the effect size was relatively small. Hence, only $\mathrm{H} 5 \mathrm{a}$ and $\mathrm{H} 5 \mathrm{~b}$ were supported.

\section{Discussion}

\section{Theoretical Contribution}

The results of the current study reveal how team flexibility is established and how such flexibility is associated with organizational outcomes. By extending the extant literature on team flexibility under an organizational change context, our study indicated that team flexibility is contingent on two factors across two levels: change leadership at team level and BD at organizational level. At the team level, change leadership predicts positively team flexibility. At the organizational level, balance dimension of organizational ambidexterity leads to more team flexibility. In addition, our results show that team flexibility significantly contributes to three organizational outcomes-change- 


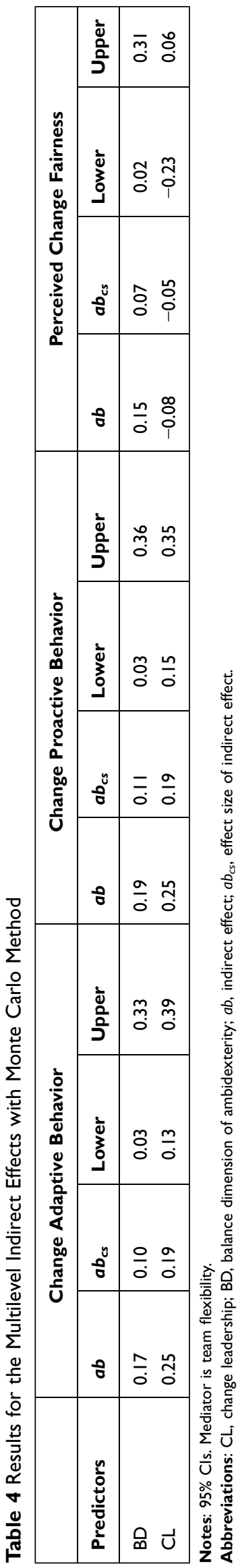

specific adaptive behavior, proactive behavior, and change fairness.

First, by examining how team flexibility is established in an organizational change context, we respond to the appeal of antecedent research in the flexibility literature. Extant research has investigated factors, which are related to the emergence of team flexibility in the field of software development, ${ }^{12}$ within-team competition, ${ }^{8}$ information system development, ${ }^{28}$ project team management, ${ }^{11}$ and so on. However, few studies have examined how team flexibility is established in the field of organizational change. We fill this gap by noting that to understand how to establish team flexibility in an organizational change context, change leadership and organizational ambidexterity that are relevant to organizational change need to be considered. Change leadership is a positive predictor for the emergence of team flexibility. This means that this change-specific leader behavior enables their work team to be more flexible during the process of organizational change. To our knowledge, our study may be the first to explore how team flexibility is established from the perspective of leader behavior. Our findings support the claim that change leadership is a good facilitator of improving team flexibility in a changing organizational environment. On the other hand, we found that BD is another predictor for the emergence of team flexibility in the process of organizational change. Considering the resourceconstrained nature of organizational change, we highlight that $\mathrm{BD}$ is a more effective and suitable strategy to promote team flexibility. That means keeping a balance between exploitation and exploration is more important for firms if they want to maintain a high level of flexibility at team level. In other words, change leadership and BD have become key antecedents of team flexibility in organizational change.

Second, we extend our research on the consequences of team flexibility in the organizational change context. Based on a cross-level analysis, our study discovers that team flexibility has good predictive validity for changespecific adaptive behavior, proactive behavior, and change fairness. Our findings highlight that team flexibility contributes greatly to organizational change outcomes, which makes a novel effort to connect team flexibility with organizational change. In other words, team flexibility is of great significance to organizational change. Although extensive research has revealed the importance of team flexibility in the organizational change, such as competitive advantage, product development, creativity and 
innovation, ${ }^{8,11,12,26}$ we know little about the effect of team flexibility on individual-level change-specific behavior and attitude. Our study is beneficial to address this gap in the literature. The analysis in this paper shows that the theory of team flexibility applies to the context of an organizational change.

Lastly, the results of this study explicate the mediator, team flexibility, connecting change leadership and $\mathrm{BD}$ to organizational change outcomes. Although extant research has recognized that change leadership and $\mathrm{BD}$ are important predictors for organizational change outcomes, ${ }^{17,22,34,43,60,73}$ scholars have not considered how team flexibility can explain the change leadership- and BD-organizational change outcome links. In fact, flexibility is ubiquitous as a rationale during the process of organizational change. ${ }^{9}$ This rationale implies that team flexibility is a core capability of and central to organizational change; and flexibility can convey powerful discourse and resilience to members within an organization. ${ }^{9}$ Our paper supports empirically this connotation that flexibility is a rationale for organizational change by considering team flexibility as a mediator of the association from change leadership and BD to organizational change outcomes. Among these indirect effects, we find that only the indirect effect of change leadership on change fairness via team flexibility is not statistically supported. This finding indicates that the indirect effect of change leadership on change fairness is not through team flexibility, but probably through other psychological mechanisms and mediations. More likely, employees' perception of change fairness is contingent on more opportunities and information provided by their leaders rather than team's capability to adapt to environment. This result provides a different view to understand the link between change leadership and change fairness in the literature.

\section{Practical Implication}

Our research has several practical implications. First, we highlight the importance of team flexibility in the process of organizational change. It may be that organizations tend to build a flexible team for the purpose of improving employees' positive action and attitude to organizational change. In doing so, employees are likely to take steps to be adaptive and proactive in organizational change and consider the change to be fair. An important takeaway is that organizations should promote flexibility in work team through introducing flexible human resource practices, such as team training. Second, our findings underlie the need for organizations to develop the capacity to balance exploitation and exploration. BD is not only beneficial for the emergence of team flexibility but also useful to promote employees' change-specific adaptive behavior, proactive behavior, and change fairness. The takeaway for ambidexterity is that organizations should be cautious about not overdrawing their resources in the change process, and they should balance new and old resources and competencies. Finally, change leadership should be considered carefully in the development of team flexibility. Our results indicate that change leadership enhances the benefits of organizational change and motivates the emergence of team flexibility. Therefore, organizations should take steps to develop change leadership. For example, human resource department may build change-oriented training program to develop change-specific leadership skills and competencies.

\section{Limitation and Future Research}

Our study is not without limitation. First, our theoretical relation testing is mainly limited to the specific situation of organizational change, which may be an advantage or a limitation. Our results reveal that hypotheses about the antecedents and consequences of team flexibility were supported in the change context. However, we know little about whether our results are generalizable to other organizational situations. Second, we used a multi-source survey method to collect data across three levels and this method is helpful to reduce the potential bias of common method. However, this method is also essentially a cross-sectional study design. Due to the lack of longitudinal sampling design, the causal inference for our results is limited to a certain extent. Therefore, future research should use a longitudinal or intensive sampling design to explore the temporal dynamics of team flexibility during the process of organizational change. Finally, we conducted this research on Chinese enterprises and employees. Due to the cultural differences between China and the West, our result may face a problem of cross-culture generalizability. We are not sure if our result can be generalized to the Western culture. Therefore, future research should consider cross-cultural comparative analysis for team flexibility. In different cultural contexts, team flexibility may have completely different antecedents and consequences.

\section{Conclusion}

Research on team flexibility has captured scholars' attention in recent years. Despite this, we still completely understand the theoretical relationships of team flexibility, especially in 
organizational change context. The current study mainly contributes to the existing literature by investigating how team flexibility is established and how important this team flexibility is to improve organizational change outcomes. Importantly, it also makes an important contribution to the literature by highlighting the fact that team flexibility provides a better understanding of why ambidexterity and change leadership are able to get employees to perceive a high level of change fairness and behave adaptively and proactively within a process of change.

\section{Ethics Approval and Informed Consent}

This study was approved by the Ethical Committee of Hohai University and adhered to the Declaration of Helsinki. In the questionnaire, we introduced the study purposes and explained that this study welcomed voluntary participation; our data, complying with the principle of confidentiality, is only used for research purposes. The survey did not begin until the participants agreed.

\section{Acknowledgments}

This study was supported by the Fundamental Research Funds for the Central Universities (B200202048).

\section{Disclosure}

There are no conflicts of interest to declare.

\section{References}

1. Allen J, Jimmieson NL, Bordia P, Irmer BE. Uncertainty during organizational change: managing perceptions through communication. J Chang Manag. 2007;7(2):187-210. doi:10.1080/ 14697010701563379

2. Krysinski PR, Reed DB. Organizational change and change leadership. $J$ Leadersh Org Stud. 1994;1(2):65-72. doi:10.1177/ 107179199400100207

3. Bordia P, Hunt E, Paulsen N, Tourish D, DiFonzo N. Uncertainty during organizational change: is it all about control? Eur $J$ Work Organ Psy. 2004;13(3):345-365. doi:10.1080/13594320444000128

4. Park S, Park S. How can employees adapt to change? Clarifying the adaptive performance concepts. Hum Resour Dev Q. 2021;32(1):E1E15. doi:10.1002/hrdq.21411

5. van den Heuvel $M$, Demerouti E, Bakker AB, Hetland J, Schaufeli WB. How do employees adapt to organizational change? The role of meaning-making and work engagement. Span J Psychol. 2020;23:e56. doi:10.1017/SJP.2020.55

6. Cloutier J, Robert-Huot G. How organizations adapt their HR practices to a changing environment: 11 theoretical dimensions to inform human resource management. Can J Adm Sci. 2021;38(3):288-302. doi: $10.1002 /$ cjas. 1608

7. van den Heuvel M, Demerouti E, Bakker AB, Schaufeli WB. Adapting to change: the value of change information and meaning-making. J Vocat Behav. 2013;83(1):11-21. doi:10.1016/j.jvb.2013.02.004
8. He H, Baruch Y, Lin C-P. Modeling team knowledge sharing and team flexibility: the role of within-team competition. Hum Relat. 2014;67(8):947-978. doi:10.1177/0018726713508797

9. Dunford R, Cuganesan S, Grant D, Palmer I, Beaumont R, Steele C. "Flexibility" as the rationale for organizational change: a discourse perspective. $J$ Organ Change Manag. 2013;26(1):83-97. doi: $10.1108 / 09534811311307923$

10. Tienari J, Tainio R. The myth of flexibility in organizational change. Scandinavian J Manage. 1999;15(4):351-384. doi:10.1016/S09565221(98)00021-9

11. Li Y, Shepherd M, Liu JY-C, Klein G. Enhancing development team flexibility in IS projects. Inform Technol Manag. 2017;18(1):83-96. doi:10.1007/s10799-016-0258-4

12. Li Y, Chang K-C, Chen H-G, Jiang JJ. Software development team flexibility antecedents. J Syst Software. 2010;83(10):1726-1734. doi:10.1016/j.jss.2010.04.077

13. Liu L, Yetton P. Sponsorship and it vendor management of projects. J Inf Technol-Uk. 2009;24(1):46-54. doi:10.1057/jit.2009.2

14. Shin J, Taylor MS, Seo M-G. Resources for change: the relationships of organizational inducements and psychological resilience to employees' attitudes and behaviors toward organizational change. Acad Manage J. 2012;55(3):727-748. doi:10.5465/amj.2010.0325

15. Orridge M. Change Leadership: Developing a Change-Adept Organization. Burlington, VT: Ashgate Publishing Company; 2009.

16. Kotter JP. Leading change: why transformation efforts fail. Harvard Bus Rev. 1995;73(2):59-67.

17. Ling B, Guo Y, Chen D. Change leadership and employees' commitment to change: a multilevel motivation approach. J Pers Psychol. 2018;17(2):83-93.

18. Barrick MR, Stewart GL, Neubert MJ, Mount MK. Relating member ability and personality to work-team processes and team effectiveness. J Appl Psycho. 1998;83(3):377-391. doi:10.1037/ 0021-9010.83.3.377

19. O'Reilly CA III, Tushman ML. Ambidexterity as a dynamic capability: resolving the innovator's dilemma. In: Brief AP, Staw BM, editors. Res Organ Behav. Vol. 28. 2008:185-206.

20. Luger J, Raisch S, Schimmer M. Dynamic balancing of exploration and exploitation: the contingent benefits of ambidexterity. Organ Sci. 2018;29(3):449-470. doi:10.1287/orsc.2017.1189

21. Weiss L, Kanbach KD. Toward an integrated framework of corporate venturing for organizational ambidexterity as a dynamic capability. Manag Rev Q. 2021. doi:10.1007/s11301-021-00223-y

22. Herold DM, Fedor DB, Caldwell S, Liu Y. The effects of transformational and change leadership on employees' commitment to a change: a multilevel study. J Appl Psycho. 2008;93:346-357. doi:10.1037/ 0021-9010.93.2.346

23. Raelin J. Leadership-as-practice: antecedent to leaderful purpose. J Chang Manag. 2021;4:1-6.

24. Gill R. Change management or change leadership? J Chang Manag. 2002;3:307-318. doi:10.1080/714023845

25. Acikgoz A, Gunsel A, Kuzey C, Zaim H. Team foresight in new product development projects. Group Decis Negot. 2016;25 (2):289-323. doi:10.1007/s10726-015-9443-9

26. Günsel A, Açikgöz A. The effects of team flexibility and emotional intelligence on software development performance. Group Decis Negot. 2013;22(2):359-377. doi:10.1007/s10726-011-9270-6

27. McComb SA, Green SG, Dale Compton W. Team flexibility's relationship to staffing and performance in complex projects: an empirical analysis. J Eng Technol Manage. 2007;24(4):293-313. doi:10.1016/j.jengtecman.2007.09.004

28. Chang K-C, Wong J-H, Li Y, Lin Y-C, Chen H-G. External social capital and information systems development team flexibility. Inform Software Tech. 2011;53(6):592-600. doi:10.1016/j.infsof.2011.01.007

29. Georgsdottir AS, Getz I. How flexibility facilitates innovation and ways to manage it in organizations. Creat Innov Manag. 2004;13 (3):166-175. doi:10.1111/j.0963-1690.2004.00306.x 
30. O'Reilly CA, Tushman ML. Ambidexterity as a dynamic capability: resolving the innovator's dilemma. Res Organ Behav. 2008;28:185-206.

31. Sanchez R. Strategic flexibility in product competition. Strategic Manage J. 1995;16(S1):135-159. doi:10.1002/smj.4250160921

32. Zolin R, Kuckertz A, Kautonen T. Human resource flexibility and strong ties in entrepreneurial teams. $J$ Bus Res. 2011;64 (10):1097-1103. doi:10.1016/j.jbusres.2010.11.026

33. March JG. Exploration and exploitation in organizational learning. Organ Sci. 1991;2(1):71-87. doi:10.1287/orsc.2.1.71

34. Cao Q, Gedajlovic E, Zhang H. Unpacking organizational ambidexterity: dimensions, contingencies, and synergistic effects. Organ Sci. 2009;20(4):781-796. doi:10.1287/orsc.1090.0426

35. Katou AA, Budhwar PS, Patel C. A trilogy of organizational ambidexterity: leader's social intelligence, employee work engagement and environmental changes. $J$ Bus Res. 2021;128:688-700. doi:10.1016/j.jbusres.2020.01.043

36. He Z-L, Wong P-K. Exploration vs. exploitation: an empirical test of the ambidexterity hypothesis. Organ Sci. 2004;15(4):481-494. doi: $10.1287 /$ orsc. 1040.0078

37. Zhao W, Feng T, Xin X, Hao G. How to respond to competitors' green success for improving performance: the moderating role of organizational ambidexterity. Bus Strateg Environ. 2021;30 (1):489-506. doi:10.1002/bse.2633

38. Levinthal DA, March JG. The myopia of learning. Strategic Manage J. 1993;14(S2):95-112. doi:10.1002/smj.4250141009

39. Yu C, Yang H, Sun H, Lin Z. Rivals or collaborators? Relational ambidexterity and absorption speed. $J$ Manage. 2021;5:01492063211021141.

40. Lee G, Xia WD. The ability of information systems development project teams to respond to business and technology changes: a study of flexibility measures. Eur J Inform Syst. 2005;14(1):75-92. doi:10.1057/palgrave.ejis. 3000523

41. Hastings BJ, Schwarz GM. Leading change processes for success: a dynamic application of diagnostic and dialogic organization development. J Appl Behav Sci. 2021;56:00218863211019561

42. van der Voet J. Change leadership and public sector organizational change: examining the interactions of transformational leadership style and red tape. Am Rev Public Adm. 2016;46(6):660-682. doi:10.1177/0275074015574769

43. Onyeneke GB, Abe T. The effect of change leadership on employee attitudinal support for planned organizational change. J Organ Change Manag. 2021;34(2):403-415. doi:10.1108/JOCM-08-2020-0244

44. Caulfield JL, Senger A. Perception is reality: change leadership and work engagement. Leadership Org Dev J. 2017;38(7):927-945. doi:10.1108/LODJ-07-2016-0166

45. Siren C, Patel PC, Wincent J. How do harmonious passion and obsessive passion moderate the influence of a CEO's changeoriented leadership on company performance? Leadersh Q. 2016;27 (4):653-670. doi:10.1016/j.leaqua.2016.03.002

46. Karp T, HelgӨ TIT. From change management to change leadership: embracing chaotic change in public service organizations. $J$ Chang Manag. 2008;8:85-96. doi:10.1080/14697010801937648

47. Armenakis AA, Bedeian AG. Organizational change: a review of theory and research in the 1990s. J Manage. 1999;25(3):293-315. doi:10.1177/014920639902500303

48. Choi M. Employees' attitudes toward organizational change: a literature review. Hum Resour Manage-Us. 2011;50:479-500. doi:10.1002/hrm.20434

49. Griffin MA, Neal A, Parker SK, New A. Model of work role performance: positive behavior in uncertain and interdependent contexts. Acad Manage J. 2007;50(2):327-347. doi:10.5465/ amj.2007.24634438

50. Ghitulescu BE. Making change happen: the impact of work context on adaptive and proactive behaviors. J Appl Behav Sci. 2013;49 (2):206-245. doi:10.1177/0021886312469254
51. Batistič S, Černe M, Kaše R, Zupic I. The role of organizational context in fostering employee proactive behavior: the interplay between HR system configurations and relational climates. Eur Manag J. 2016;34(5):579-588. doi:10.1016/j.emj.2016.01.008

52. Bohlmann C, Zacher H. Making things happen (un) expectedly: interactive effects of age, gender, and motives on evaluations of proactive behavior. $J$ Bus Psychol. 2021;36(4):609-631. doi:10.1007/s10869-020-09691-7

53. Caldwell SD, Herold DM, Fedor DB. Toward an understanding of the relationships among organizational change, individual differences, and changes in person-environment fit: a cross-level study. $J \mathrm{Appl}$ Psychol. 2004;89(5):868-882. doi:10.1037/0021-9010.89.5.868

54. Fugate M, Prussia GE, Kinicki AJ. Managing employee withdrawal during organizational change: the role of threat appraisal. J Manage. 2012;38:890-914.

55. Liao H-P, Pan X-F, Yin X-Q, Liu Y-F, Li J-Y, Wang J-L. Decreased COVID-related adaptive behavior and increased negative affect: a multivariate latent growth curve model. $J$ Health Psychol. 2021;135910532110216. doi:10.1177/13591053211021651

56. De Clercq D, Khan MA, Haq IU. Perceived organizational politics and turnover intentions: critical roles of social adaptive behavior and emotional regulation skills. J Manage Organ. 2021;2:1-19.

57. Wadhwa S, Rao KS. Towards a proactive flexibility management view. Glob J Flex Syst Manag. 2002;3(2/3):1-10.

58. Faupel S, Helpap S. Top management's communication and employees' commitment to change: the role of perceived procedural fairness and past change experience. J Appl Behav Sci. 2020;57(2):204-232. doi: $10.1177 / 0021886320979646$

59. Schminke M, Cropanzano R, Rupp DE. Organization structure and fairness perceptions: the moderating effects of organizational level. Organ Behav Hum Dec. 2002;89(1):881-905. doi:10.1016/S07495978(02)00034-1

60. Kauppila O-P. Creating ambidexterity by integrating and balancing structurally separate interorganizational partnerships. Strateg Organ. 2010;8(4):283-312. doi:10.1177/1476127010387409

61. Podsakoff PM, MacKenzie SB, Jeong-Yeon L, Podsakoff NP. Common method biases in behavioral research: a critical review of the literature and recommended remedies. J Appl Psychol. 2003;88 (5):879. doi:10.1037/0021-9010.88.5.879

62. Patel PC, Messersmith JG, Lepak DP. Walking the tightrope: an assessment of the relationship between high-performance work systems and organizational ambidexterity. Acad Manage J. 2013;56 (5):1420-1442. doi:10.5465/amj.2011.0255

63. Shinkle GA, Goudsmit M, Jackson CJ, Yang F, McCann BT. On establishing legitimate goals and their performance impact. $J$ Bus Ethics. 2019;157:731-751.

64. Eichhorn BR. Common Method Variance Techniques. Cleveland, OH: SAS Institute Inc.; 2014.

65. Bliese PD. Within-group agreement, non-Independence, and reliability: implications for data aggregation and analysis. In: Klein KJ, Kozlowski SWJ, editors. Multilevel Theory, Research, and Methods in Organizations: Foundations, Extensions, and New Directions. San Francisco, CA, US: Jossey-Bass; 2000:349-381.

66. James LR, Demaree RG, Wolf G. Estimating within-group interrater reliability with and without response bias. $J$ Appl Psychol. 1984;69:85-98. doi:10.1037/0021-9010.69.1.85

67. Chen G, Bliese PD. The role of different levels of leadership in predicting self- and collective efficacy: evidence for discontinuity. J Appl Psychol. 2002;87:549-556. doi:10.1037/0021-9010.87.3.549

68. Raudenbush SW, Bryk AS. Hierarchical Linear Models: Applications and Data Analysis Methods. 2 ed. Thousand Oaks, CA: Sage; 2002.

69. Zhang Z, Zyphur MJ, Preacher KJ. Testing multilevel mediation using hierarchical linear models: problems and solutions. Organ Res Methods. 2009;12:695-719. doi:10.1177/1094428108327 450 
70. Pituch KA, Murphy DL, Tate RL. Three-level models for indirect effects in school- and class-randomized experiments in education. $J$ Exp Educ. 2010;78(1):60-95. doi:10.1080/00220970903224685

71. Selig JP, Preacher KJ. (2008, June). Monte Carlo method for assessing mediation: An interactive tool for creating confidence intervals for indirect effects [Computer software]. Available from: http:// quantpsy.org/.
72. Preacher KJ, Kelley K. Effect size measures for mediation models: quantitative strategies for communicating indirect effects. Psychol Methods. 2011;16(2):93-115. doi:10.1037/a0022658

73. Stettner U, Lavie D. Ambidexterity under scrutiny: exploration and exploitation via internal organization, alliances, and acquisitions. Strategic Manage J. 2014;35(13):1903-1929. doi:10.1002/smj.2195

\section{Publish your work in this journal}

Psychology Research and Behavior Management is an international, peer-reviewed, open access journal focusing on the science of psychology and its application in behavior management to develop improved outcomes in the clinical, educational, sports and business arenas. Specific topics covered in the journal include: Neuroscience, memory and decision making; Behavior modification and management; Clinical applications; Business and sports performance management; Social and developmental studies; Animal studies. The manuscript management system is completely online and includes a very quick and fair peer-review system, which is all easy to use. Visit http://www. dovepress.com/testimonials.php to read real quotes from published authors.

Submit your manuscript here: https://www.dovepress.com/psychology-research-and-behavior-management-journal 